the foot on which the limb rested. Pulsation in the tibial arteries remained absent.

On Dec. Ist the wound was quite healed, and the patient was allowed to leave his bed, and go about the ward on crutches. There was a little weakness of the foot, but the knee-joint and limb were perfectly movable and strong.

On Dec. 26 th the patient walked freely without support on the affected limb, the foot of which still remained somewhat weak.

Remarks.-The case just reported is one of great importance in connexion with the surgery of the bloodressels. The absence of the peculiar thrill which has always been considered diagnostic of arterio-venous aneurism is a point of interest. Had the operation not so distinctly disclosed the presence of a wound in both artery and vein, I and those who saw the case would have looked upon it as one of teaumatic aneurism of the popliteal artery. The reported cases of traumatic arterio-venous aneurism of the large arteries are not numerous, but in most of these, as far as I can ascertain, this symptom was observed, and directed attention to the true nature of the case. An examination of the wounded popliteal vein, made at the time of the operation, did not discover any appreciable dilatation of its canal, such as has usually been noticed in arterio-venous aneurism, and therefore $I$ am inclined to think that, although a wound in both artery and vein communicating with the aneurismal sac existed, there was little or no communication through these wounds between the arterial and venous circulation. This conjecture may be explained by the Iongitudinal direction of the wound in the vein, and its position in regard to the corresponding wound in the artery. Be the explanation what it may, the fact of the absence of the peculiar thrill in this instance must be considered as quite exceptional in connexion with arterio-venous aneurism.

The most instructive part of this case is a consideration of the treatment which was successfully adopted. Mr. Folmes, * in his very valuable lectures on this subject, directs attention to the methods of treatment which have been employed in cases of arterio-venous aneurism of the femoral vessels. These methods may be enumerated as (1) ligature of the artery after the Hunterian plan, (2) compression, (3) ligature of the artery above and below the sac without opening the latter, (4) laying open the sac and tying the artery above and below the wound, the vein not being interfered with.

A consideration of the treatment of the reported cases of arterio-venous aneurism shows that the first of these operations has proved most unsatisfactory; that the second, when it can be applied accurately, so as to cause obliteration of the venous communication, has proved and is likely to be useful; that the third, although it has proved successful, $\uparrow$ is only applicable in certain cases, and necessitates a difficult dissection; that the fourth, although it has proved successful, $t$ is attended with great risks-(1) from venous hæmorrhage, (2) from purulent absorption.

The method employed in the case related has, as far as I am aware, never before been practised, but it is only just to state that $\mathrm{Mr}$. Holmes, $\S$ in his remarks, suggests the advisability of this proceeding, and refers to instances where both arteries and veins have been obstructed or ligatured without bad consequences following.

The result of the operation in my case tends to prove that surgeons have taken a too serious view of the risks likely to follow the ligature or obstruction of the principal artery and vein of a limb. One principle in all former operations for the relief of arterio-venous aneurism has been to avoid any interference with the vein, but this case has now practically demonstrated that both artery and vein may be sucsessfully ligatured.

Should carefully-applied compression fail to relieve an arterio-venous aneurism, my recent experience inclines me to advocate the operation performed in the present instance, provided the case be one otherwise suitable for an operation.

The advantages of this plan are, in my opinion, (1) certain closure of the openings of communication in both artery and vein; (2) absence of any risk from venous hæmorrhage or absorption in connexion with the wounded vein; (3) its

\footnotetext{
* The Lavces, October 17th, 1874.

+ Mr. Spence's case (Lectures on Surgery, p. 625)

\$ See Mr. Holthouse's case (British Medical Journal, May 7th, 1859).
\$ Lec. eit.
}

practicability in the large majority of cases; (4) its easy performance without murh dissection.

By the employment of the antiseptic treatment in the present case, all local irritation in connexion with the sac and wound was prevented, and suppuration was limited to the single discharge of a few drops of innocent pus.

In consequence of these facts, I consider myself justified in attributing to this treatment much of the success of the case, and I would therefore recommend its adoption with great confidence in this class of operation.

Edinburgh.

\section{CASE OF \\ PHTHISIS TREATED BY PHOSPHORATED COD-LIVER OIL.}

Br JOHN C. THOROWGOOD, M.D., F.R.C.P., PHXSICIAN TO VICTORIA-PARK HOSPITAL FOR OISEASES OF THE CHEST, ETC.

Mr. F-, aged twenty, had in his boyhood suffered from disease in the bones of the leg; fragments of bone had from time to time become detached, and the apertures had, after many months, cicatrised, and remained so to the date given below.

In March, 1869, I saw this gentleman in consequence of a troublesome cough, attended with copious yellow expectoration every morning, often mixed with florid blood. His pulse was 100 ; his tongue white; and he looked pale and emaciated. Left chest resonant; respiration full and strong. Right apex : impaired resonance, strong bronchial breathing and bronchial voice; behind, crepitant râle is beard at supra-spinous fossa. Ordered to take two drachms of Savory and Moore's phosphorated cod-liver oil* three times a day, and a tonic mixture of quinine with dilute phosphoric acid.

He was not seen again till January, 1870. At that date he said he had scarcely any cough, and had gained in flesh and weight. Pulse 104. Left chest normal. Right apex dull, with bronchial respiration at infraclavicular region, and slight crepitant râle behind. He had taken a few bottles of the quinine tonic, and had continued the phosphorated oil, with occasional intervals.

He went on well till June, 1871, when I was called to him at his home in the country in consequence of severe bæmoptysis; being away from town I did not, bowever, see him till "September, 1871 , when he came to me. The bæmoptiysis continued for some time, and he was attended by Mr. R. Perrey, of Marden. When I examined him I found the physical signs not much changed. Crepitation was distinct and limited to right apex. He was ordered some tincture of iron, but this made him feverish, and caused a return of the bleeding; it was therefore stopped.

In December, 1872, I again saw him, and from this time up to March, 1873, be was feverish, pulse often 120, temperature in mouth $101^{\circ}$, much shortness of breath, loss of appetite, expectoration, and occasional hæmoptysis.

On examining the chest (March, 1873), there were cavernous breathing, loose crepitation after cough, pectoriloquy, and "crack pot" note, all as well-marked signs, in right upper third of chest. He was now taking the phosphorated oil, and no other medicine. The physical signs being so strictly limited to the right upper third, I considered that a deposit had softened here, and that this process had caused the rise of temperature, and other symptoms. There seemed no sign of mischief in the left lung, and $I$ advised the continuance of the oil, and perfect rest at home. The quinine and phosphoric acid were again administered.

June 1st, 1873.-Palse 100 ; cough much less; appetite good; much less crepitation in right chest; left normal. Finds the phosphorated oil agree well, and he desires to continue it. Recommended to go to Harrogate, and take a tonic of nitric acid and cascarilla.

Sept. 19th, 1873.-Returned from Harrogate, where he gained $8 \mathrm{lb}$. in weight during seven weeks. Cough much less; pulse 92. Says he does not get nearly so hot as he

\footnotetext{
* Containing one-fifth of a grain of phosphorus in the ounce.
} 
did. On examining the chest, the eye is struck by the falling-in of the chest-wall on the right side; dry, bollow breathing is heard over the flattened part. Has left off the oil for some weeks; but is now to resume it again in doses of four drachms twice daily.

March, 1874. - Slight orackling after cough in right chest; pulse 100. Apparently a cold has set up a littlo irritation there.

June.-Complains only of slight morning cough, and has continued in good health up to the present date.

The case seemed to me of interest in connexion with the antecedent bone disease. This got quite well, and then signs of a deposit appeared at the right apex. Congestion of the apex was induced, with bæmoptysis, and eventually breaking down of the deposit, with a cavity as the result. This cavity appears to have contracted; and thus the patient has got into, what appears to all, a very good state of health.

The treatment was by no means complicated. Iron, whenever tried, seemed to do no good; but the liking acquired for the phosphorated cod-liver oil was very marked, and I was surprised at the persistence with which it was taken without any nausea resulting. To the use of this oil and to the effect of the dry tonic air of Harrogate, after inflammatory symptoms had subsided, I attribute the recovery.

Welbeck-street, W.

\section{ON THE}

\section{USE OF A STYLE IN OBSTRUCTIONS OF THE LACHRYMAL APPARATUS.*}

BY JOHN A. NUNNELEY, M.B. LOND.,

SENTOR OPFTHATMIC AND ADRAT SURGBON TO THE LEEDS GWNERAT IN FIRMARY.

IT is not my purpose now to speak of affections of the lachrymal apparatus in general, but only of one method of treatment of those diseases of the sac or nasal duct in which dilatation of the latter by mechanical means is necessary.

The difficulty formerly experienced in dealing with such cases is sufficiently shown by the great variety of probes of metal and catgut, of many shapes, and to be used in various ways, and of styles, and tubes, and other mechanical appliances, which were devised, often with great ingenuity, with the object of dilating and keeping open the nasal duct. Except the simple style, introduced through the skin and the anterior wall of the lachrymal sac, these contrivances failed more or less in their object, and were abandoned. In many respects the treatment by the style was satisfactory enough. It had, however, some objections: its appearance was unsightly, it was liable to fall out or be dragged out in various ways, and after its removal in some instances the opening which was left refused to heal, and a lachrymal fistula was the result. Since the general introduction of the very simple and admirable operation of division of the canaliculus into the lachrymal sac, devised by Mr. Bowman, the description of which was published in the Transactions of the Royal Medico-Chirurgical Society for 1851, the treatment of cases of epiphora, depending upon displacement of the puncta or obstructions of the canaliculi or nasal duct, has been reduced to narrow limits, this plan presenting such conspicuous advantages as to have been almost at once generally adopted. By it the sac and nasal duct can be reached and treated through the natural passages, without external wound. The advantages guined by this mode of procedure are many, and its disadvantages few. The latter are, mainly, that in order to keep open the wound along the canaliculus, which has been divided, it is necessary to pass a probe along it several times, or the incision will close (as it frequently does unless considerable care be taken); again, the probe must be passed through the nasal duct at intervals, longer or shorter according to the nature of the stricture. All this involves, of course, considerable pain, and is more or less tedious, usually re-

* Abstract of a paper communicated to the Leeds and West Riding Medico-Chirurgical Society. quiring several attendances on the part of the patient, so that there is of tentimes difficulty, both in public and private practice, in persuading persons to persevere for a sufficient length of time.

These objections may be avoided, and the whole treatment greatly simplified, in most instances, by the use of a form of style introduced some years ago, I believe, by Mr. R. Taylor, surgeon to the Central London Ophthalmic Hospital, and which has scarcely, I think, been adopted so frequently as it deserves. It is highly spoken of by $\mathbf{M r}$. Haynes Walton, in his work on the "Surgical Diseases of the Eye." This style is a straight piece of silver to fit the nasal duct, having at right angles to it, at the upper end, a small arm about three-eighths of an inch in length; it is introduced along the slit-up lower canaliculus, through the lachrymal sac into the duct. The little horizontal arm lies in the channel of the canaliculus, which it keeps open, and prevents the style from slipping out of sight, allowing ready removal when necessary. I have used it constantly, and with great advantage. The canaliculus is slit up in the usual way, and I then either dilate for a short time with the ordinary probe, and then put in the style, or more generally, where the case is a straightfor ward one, introduce the latter at once. Different sizes are required. The style requires to be taken out and cleaned occasionally, and if there be any irritation set up by it, which is not common, the removal of it for a day or two is generally sufficient to allow it to be worn with ease, and $I$ find that patients are so comfortable while wearing it that they of ten neglect to appear at the end of a month or six weeks to have the in. strument removed.

When we think of the very fragile bones by which the lachrymal apparatus is formed, and the danger which must always existlest the passing of an instrument should injure them, or bruise their delicate lining membrane, the consequent swelling of which would increase, instead of lessening the evil, it must be evident that the use of a probe in this situation demands the greatest gentleness. A plan therefore which so much simplifies the instrumental treatment of many of these frequent, painful, and troublesome cases is a real gain.

Leeds.

\section{Stedircal Sucteties.}

\section{ROYAL MEDICAL AND CHIRURGICAL SOCIETY.}

The ordinary meeting of this Society was held on April 13th, the chair being filled by the President, Sir James Paget. There was an unusually large attendance of fellows and visitors, the latter including a number of well-known army surgeons, many of whom had come from a distance to be present at the reading of the paper of the evening.

The paper read was by Mr. AcToN, "On the Prevalence and Severity of Syphilis among the Troops quartered in London, as compared with the Rarity of the Disease among the Soldiers in the Garrisons of Paris and Brussels; from observations, the result of a personal investigation made during the autumn of 1874." He stated that, on returning to England after the completion of his medical studies in Paris, he was forcibly" struck with the severity and the number of cases in an unprotected city like London, as contrasted with a protected city like Paris. [The following definitions of these terms were then given:-." The term unprotected district is meant to include the principal cities of the United Kingdom where women can practise prostitution in any public thoroughfare at any hour of the day or night, without hindrance, and inveigle men to their homes; and this, too, under the very eyes of the authorities, who are powerless to interfere, unless the solicitation be to the annoyance of any passenger or householder, who must in that case accompany the police to the station to charge the woman with the offence, which is rarely or never done. Should the authorities have credible evidence that the 